\title{
ABSTRACTS
}

\section{I.-TRACHOMA IN PALESTINE}

Ticho, I. and Kligler, I. J.-Trachoma in Palestine. Lancet, September 30, 1922.

In this article dealing with trachoma in Palestine, the incidence of which is not definitely known, the first-named author deals with diagnosis and treatment, while the second deals with aetiology, transmission and control. The diagnosis is, as we all know, difficult. According to Ticho, to the practised eye the difficulty is not really as great as it may appear. " The cicatrice in the sulcus subtarsalis is so characteristic that a diagnosis can be readily made by lifting the upper lid; this cicatrice resembles a chain of hyphens. The presence of solid follicles typically localized (sulcus subtarsalis, transition folds, conjunctiva of the tarsus, plica semilunaris) is also diagnostic. Soft granules, cicatrice and papillae which resist treatment are all diagnostic. Nevertheless many cases must remain doubtful." Dealing with mixed infection this author says that the acute papilla and the acute pannus in apparently cured cases of trachoma which accompany the Weeks trachoma mixture affect favourably the course of the trachoma. And, also, that although gonococcal infections are the chief cause of blindness, in many cases, when mixed with trachoma, they protect the eyes against total blindness by the appearance of acute pannus, which covers the cornea with a protective film and prevents destructive ulceration.

Kligler admits at the outset that the aetiology of trachoma is undetermined. From observations in Palestine it appears to be a specific contagious disease. The important statement is made that fresh uncomplicated trachoma is seen especially in young children of pre-school age. Up to the present, material from uncomplicated cases has elicited no reaction when injected into rabbits. Unlike other forms of conjunctivitis trachoma does not occur in epidemic form in Palestine. Since trachoma is chiefly a disease of children, control means thorough supervision of the sch this has resulted in the reduction of the trachoma incidence in the school from 31.3 per cent. in 1913 to 13 per cent. in 1916, though during the war it rose again to 21.7 in 1919 and 20.1 in 1921. While the incidence is thus reduced by steady and continuous treatment the problem of the prevention of new infection presents many difficulties. Just at the time when the incidence of new infections is greatest the child is not under the supervision of either 
physician or nurse. Successful attack upon the disease necessitates visiting the homes and families of children who are constantly exposed to infections, and examining and treating the families as well as the children of pre-school age. In this way the disease can be found at its onset and its progress intercepted. The author refers to the importance of education as an element in the treatment of trachoma. Education in the value of cleanliness should prove helpful, but it has so far been little employed in Palestine. Another factor, the significance of which is as yet obscure, is diet. The experiments of Osborn and Mendel and of McCollum on the relation of dietary deficiency to conjunctivitis are, the author considers, highly suggestive and promise to open a new approach to a difficult problem.

ERnest Thomson.

\section{II.-HYPERTHYROIDISM AND AMETROPIA}

\section{Sourasky, A. (Sheffield). - On errors of refraction in hyper- thyroidism.-Lancet, September 16, 1922.}

Sourasky has studied 20 cases of hyperthyroidism (16 of which had exophthalmos) with a view to the ascertainment of the refractive condition, and expected to find that in exophthalmos the loss of balanced pressure to which the eye is normally subject would lead to changes in its contour. The expectation seems to have been realized since, out of the 32 exophthalmic eyes, 29 were astigmatic. Further, myopic astigmatism was in undue proportion 12 eyes having myopic and 14 hypermetropic astigmatism. Of the 4 cases (8 eyes) without exophthalmos, 6 had compound hypermetropic astigmatism, 1 compound myopic astigmatism, and 1 myopia. The axis of the astigmatism "does not seem to follow a certain course, as one would expect if it were due to pressure of the lids on the protruding eyeball. Furthermore, it was present in i out of 8 eyes where there was no exophthalmos." Out of the 40 eyes examined 36 were astigmatic. The author concludes that hyperthyroidism causes astigmatism, but is unable to decide whether the astigmatism is a general manifestation or is caused by the changed local conditions. Dealing with hyperthyroidism and headache the author says: "The almost constant presence of astigmatism in the hyperthyroid state would lead one to expect that these patients should suffer from headaches. And this is indeed the case. Out of the 16 patients with exophthalmic goitre 13 suffered in this respect. Out of the 4 hyperthyroid patients, 3 
were subject to headaches. Moreover, all the patients who had their astigmatism corrected reported the disappearance of this symptom. And more than this, many patients stated that they feel much better generally since wearing glasses. It is quite conceivable that much good can follow the correction of astigmatism in patients whose nervous system is unstable, as it is in hyperthyroidism. This would be so irrespective of whether the hyperthyroidism caused the astigmatism, or whether the symptoms of a pre-existing astigmatism were merely brought out by the hyperthyroidism."

Ernest Thomson.

\section{III-AMAUROSIS IN INFANTS}

Doyne, P. G. (London). - Amaurosis in infants. Lancet, September 16, 1922.

Doyne deals with amaurosis in infants, that is, amaurosis not associated with an obvious ocular lesion such as cataract, malformation of the eye, or gross retinal disease. The cases include amaurosis with mental deficiency, partial albinism (defective fundus pigmentation), and temporary amaurosis associated with basal meningitis, followed by recovery. Five illustrative cases are recounted. The author opens his lecture, which was delivered at the Hospital for Sick Children, Great Ormond Street, with a reference to the development in the child of the faculty of vision and the fusion sense. In this connection the reviewer is inclined to quarrel with the author for the following sentences: "Binocular vision, or, in other words, the desire for fusion of the images of the two eyes, continues to develop up to the age of 6 . This is significant when dealing with cases of squint, in which absence of the faculty of fusion is the underlying cause, as, after the age of 6 , attempts to improve this faculty will fail." Such a presentation of the case, legitimate enough if given to a purely specialist audience, seems unwise where the audience is non-specialist, as it presumably was in this instance. A non-specialist would be extremely likely to understand from hearing or reading the statement that it is useless to bother about the treatment of squint after the age of 6 years. Such an interpretation of the author's meaning would presumably be incorrect.

ERNest Thoison. 


\section{IV.-RETINAL ANGIOSCLEROSIS}

Copps, L. A., M.D. (Marshfield, Wisconsin).-Retinal angiosclerosis. Amer. Jl. of Ophthal., November, 1921. Series 3, Vol. IV, No. 11.

Copps gives an interesting summary of the pathology and ophthalmological appearances of angiosclerosis of the retina, with the report of six illustrative cases. In a preliminary paragraph he points out that the presence of angiosclerotic changes in any part of the body, however limited locally in their manifestations, is but the evidence of general disturbance, and the study of such changes in the retina is chiefly of interest from its general and prognostic value. He gives the three greatest causes of sclerotic changes in blood vessels thus :-

1. Intoxications.

2. High blood pressure.

3. Senility.

After a short sketch of the pathology of the condition as it affects the retinal vessels Copps goes on to discuss the ophthalmoscopic appearances of vascular changes in the retina, distinguishing between hypertension unaccompanied by arterio-sclerosis, in which the vessels tend to become uniformly distended, angiosclerosis, in which the walls of the vessels are thinned and relaxed, and the late stage of hyperplastic rigidity.

The ophthalmoscopic appearances in each of these conditions is given with considerable detail. The significance of vascular disease of the retina in the interpretation of general vascular disease is dealt with, and the literature briefly reviewed. The paper ends with the history of six cases occurring in the experience of the author. In all of these, with one exception, the general condition was found by first detecting the retinal changes. The paper is illustrated with the fundus view of each case.

\section{J. Hamilton McIlroy.}

\section{V.-PHAKOERISIS}

de St. Martin (Toulouse).-Barraquer's phakoerisis. (A propos de la phakoerisis de Barraquer). La Clin. Ophtal., September, 1921.

It is not so long since oculists from far distant parts of the world made the pilgrimage to Amritzar in order to learn at first hand how Smith extracted the lens in its capsule. Now it is the turn 
of Barcelona, where, evidently, Barraquer is extracting lenses in the capsule by the thousand by his suction method. New methods at first may seem simple; then it transpires that there are difficulties, and one finds men having to make the pilgrimage in order fully to appreciate these, and to learn from the master. St. Martin, like many others, has been impressed with the importance of the Barraquer operation, and has completed a period of study at Barcelona. It is evident, reading between the lines, that he has not found the method so simple as might be expected from the published accounts. That the results in the hands of Barraquer are really excellent there seems to be no doubt. Thus, of twelve patients operated on in one day., five obtained V.A. 10/10, three obtained $9 / 10$, two obtained $8 / 10$, one obtained $7 / 10$, and one obtained $5 / 10$. Further, of these twelve cases seven were able to read No. 1 print at periods varying from the tenth to the twentieth day. Yet St. Martin, referring to his own results, is quite guarded, offering no opinion " because his operations have been as yet few in number." Points of technique occupy four pages of St. Martin's article, which may be referred to by any who propose to attempt the operation. It will suffice here to emphasise what seem to be the most important, namely: (1) To obtain by early employment (three hours before operation) of euphthalmin, sufficient " inertia" of the iris, a sufficiently complete "pupilloplegia"; (2) to avoid the least pressure on the globe, by paralysing the orbicularis by means of the van Lint-Villard technique, and by discarding the blepharostat in favour of the retractor of Desmarres; (3) to make a clean section of the cornea and, most difficult of all, to make a peripheral iridectomy on an iris which is under the influence of a mydriatic. Understood, of course, that a complete iridectomy can be made if desired; (4) to be careful with the wound toilette, and, in particular, to allow no blood to remain in the anterior chamber. Of the actual extraction of the lens by the suction apparatus St. Martin says little. He points out, however, that if, for any various reasons, the sucker lets go it can, given sufficient delicacy of manipulation, be reapplied without danger. In one case where the zonule was extremely resistant the sucker let go eight times before the extraction could be completed, and that without loss of vitreous.

(NoTE.-The van Lint method of paralysing the orbicularis consists in injecting $4 \mathrm{cc}$. of 2 per cent. novocain close to the bone at the lower and outer margin of the orbit where lie the malar branches of the facial nerve which supply the orbicularis. See Report of meeting of Soc. française d' Ophtal., May, 1921, in La Clin. Ophtal., July, 1921, and also Quain's Anatomy, 9th Edition, Vol. I, p. 573.-E. T.)

ERnest Thomson. 


\section{VI.-SYMPATHETIC IRIDOCYCLITIS}

\section{Harbridge, D. F.-Sympathetic iridocyclitis and possibly related processes in other parts of the body. Amer. Jl. of Ophthal., April, 1919.}

Harbridge advocates the view that the essential causative agent of sympathetic iridocyclitis is to be found in tissues other than those of the injured eye, and that trauma, or ulcerative processes, which usually are looked upon as the main cause of the disease, are possibly only contributory factors.

He points out that clinically sympathetic iridocyclitis does not differ from so-called idiopathic or non-traumatic iridocyclitis. Out of 400 patients having injury of the eyeball, the writer has met with only one case of sympathetic inflammation, although he has had several cases of irritation in which removal of the injured eye led to cessation of the signs. He questions whether, if left to run their course, such cases would have developed sympathetic iridocyclitis.

He quotes a case of severe plastic iridocyclitis in which, as the signs of inflammation began to subside in the affected eye, typical signs developed in the fellow eye. Nothing amiss could be found in the general condition with the exception of two teeth which exhibited apical abscess. Removal of these teeth was followed by complete recovery of the eye condition.

Another case in which sympathetic inflammation developed some months after cataract extraction was found to have many decayed septic teeth, with alimentary disturbance. Harbridge emphasises the need for careful examination of the condition of the nose, throat, etc., in order to detect possible foci of infection. He questions whether sympathetic disease is due to any specific cause, being inclined to the view that it is a secondary disturbance due to local changed metabolism, the source being either in the uvea of the injured eye, or in some other part of the body. Every injury of the eye may be accompanied by a low-grade inflammation of the fellow eye, which causes the tissues of the latter to be more susceptible to bacterial invasion on account of lowered resistance. Not every wound of the uveal tract is followed by sympathetic trouble; many such wounds heal and remain quiet. They cannot all be aseptic, but the bacteria in certain cases may be more benign than in others, or may possess greater affinity for uveal tissue. If the bacteria were all virulent at the time of injury, prompt destruction of the injured eye would follow. Streptococci or other micro-organisms may affect the injured uvea at the time of injury; these may be derived from another focus (teeth, etc.), and it is only after a length of time that they develop 
affinity for the corresponding tissue of the other eye. He reasons that the exciting eye, if still endowed with a certain amount of serviceable vision, should not be enucleated, since amelioration of the symptoms in the sympathising eye does not appear to be certain. Only an exciting eye which is useless should be enucleated.

With reference to anaphylaxis, he draws attention to the decrease in frequency of sympathetic disease, and is of opinion that this fact in itself speaks against anaphylaxis as a cause.

\section{J. Hamilton McIlroy.}

\section{VII.-LEBER'S DISEASE}

Lagrange, Henri.-Hereditary optic atrophy (Leber's Disease). (De l'atrophie optique héréditaire : maladie de Leber). Arch. d'Obhtal., September, 1922.

Apropos of the report of a case, Lagrange reviews briefly but clearly much of the published work on the clinical characters and pathogenesis of this disease. His patient was a male aged 18, who presented the well-known clinical features of the disease; vision was reduced to $1 / 10$ in the right and to $1 / 2$ in the left eye. Two of his maternal uncles were similarly affected, but no information was obtainable regarding previous generations. Lagrange made an exhaustive examination of his patient; several radiographs of the region of the sella Turcica and hypophysis were taken, but revealed no abnormality; measurements of the skull showed that its contour and proportions were normal. Haematological examination, however, revealed a notable abnormality; while the blood count was within normal limits, the coagulation rate was markedly retarded, and the clot formed was feebly retractile. Three measurements (the blood being withdrawn under exactly similar conditions) showed a retardation in coagulation of 26 minutes, 24 minutes, and 25 minutes. From the weakly coagulum a thin transparent yellow serum exuded.

These haematological findings are similar to those obtained in cases of haemophilia. The author considers as most noteworthy the discovery in the subject of an hereditary malady; transmitted by the mother according to Mendelian laws, a pathological condition of the blood, which, though it has not elucidated the pathogenesis of haemophilia, is looked upon as its haematological characteristic.

As hereditary disorders Leber's disease and haemophilia are 
comparable. Both are almost sex-limited, and are transmitted by unaffected females to their male children.

Lagrange's patient was treated actively by thyroid extract in increasing doses for a period of six weeks. He exhibited perfect tolerance of the drug, and its administration was followed by an improvement in the sight of the right eye from $1 / 10$ to $1 / 2$, but the vision of the lett eye deteriorated slightly (from $1 / 2$ to $1 / 3+$ ).

Lagrange counsels the early adoption of organo-therapy in cases of Leber's optic atrophy.

J. B. LAWFORD.

\section{VIII.-THE ZONULE}

\section{Beauvieux (Bordeaux). The Zonule. A topographical and histological study. (La Zonule. Étude topographique et histologique). Arch. d'Ophtal., July-August, 1922.}

After studying numerous works of previous investigators the writer found the subject so complex and difficult that he decided to undertake an independent research concerning the zonule. In a long, interesting and well-illustrated paper he reports the result of his studies : they support in many points the researches of others and present some original observations which he hopes may be subsequently confirmed. The paper extending to more than $26 \mathrm{pp}$. is so long and detailed that it would be very difficulty to deal fairly with it in an abstract. It will repay perusal by those interested. We give here, somewhat curtailed, the "Physiological and Clinical Deductions " with which the author concludes his paper and in which he expounds his views. In it he refers to certain topographical and histological features described by him in the earlier part.

1. The suspensory system of the lens is wholly contained in the posterior chamber. It is an autonomous apparatus and forms a veritable peri-crystalline canal with proper walls composed of the fibres of the zonule cemented together by an amorphous substance without apparent structure. The cavity of this canal traversed by the equatorial and para-equatorial fibres is occupied by a semi-fluid material, structureless, very transparent and very hygrometric, differing in its characters from the aqueous humour which fills the peri-zonular space, and resembling vaguely the vitreous humour. The author does not accept the view that the zonule consists of a series of filaments with intervening fissures, through which the aqueous freely circulates. He holds that the aqueous, secreted or transuded at the level of the ciliary processes, penetrates by osmosis into the canal of Hannover and leaves it by the same process. 
Without considering the peri-equatorial canal as a lymphatic channel it is nevertheless reasonable to allow that the circulation of the aqueous humour is regulated by the anatomical arrangement of the suspensory ligament as described by Beauvieux, and that this arrangement plays a considerable rôle in the nutrition of the lens.

In an article on the circulation of intraocular lymph, apropos of the experiments of Bono and Frisco with coloured injections, Angelucci says, "Another portion of the colouration surrounds the crystalline lens following the peri-lental space, whence it apparently should join the central canal of the papilla. . . . Injections into the vitreous showed that the colour spreads around the zonule of Zinn to reach the periphery of the iris." In this connection, moreover, the experiments of Samelsohn and Fuchs should be recalled. These observers, introducing particles of iron into the vitreous, were able to see particles of rust close to the equator of the lens forming a sort of coronet corresponding exactly to the anterior border of the zonule. Schlösser concluded that the nutritive fluids of the lens escaped at the level of pre-equatorial apertures into the posterior chamber. There is no doubt that the peri-crystalline inter-zonular canal provides the afferent and the efferent path of the nutritive fluids of the lens, the flow of which Beauvieux believes is regulated by osmosis. He has never been able to discover the existence of apertures. In a case of iridocyclitis in a child of 12 , he found the zonule fibres, their cementing material and the cavity of the canal, crotwded with epithelial detritus and red and white corpuscles, which in sections mapped out exactly the peri-equatorial triangular ligament. It is much to be desired that more extended physiological investigation should be undertaken to determine the function of the inter-zonular space, alterations in which consecutive to those in the ciliary body, certainly play a preponderating rôle in the genesis of cataract.

2. The arrangement of the zonule fibres, the position of their principal insertion on the pars plana of the retina and their close connection with the ciliary muscle favour the Helmholtz theory of accommodation. In distant vision the zonule is in a state of relative tension, the ciliary muscle being then at rest, either naturally or through inhibition of the sympathetic. During accommodation, on the contrary, the zonule is relaxed: from the anatomical point of view it could not be otherwise. Some of the author's mitrophotographs show definitely that the attachment of the zonule fibres extends from the limit of the ciliary ridges and hollows as far as the ora serrata. Contraction of the ciliary muscle draws forward the choroid, the pars plana, and even to a certain degree the peripheral portion of the vitreous. Relaxation of the zonule fibres follows inevitably. The anterior fibres and the greater part of the posterior start from the orbiculus ciliaris : a few bundles of the 
posterior fibres, it is true, arise a little further forward immediately behind the summit of the processes, but never in the hollows or on the ridges. These bundles also are relaxed in accommodation. Hess in an iridectomised eye under eserin has seen the ciliary processes displaced forwards to a point well in front of the equator of the lens. Similarly Heine in the monkey and Beauvieux in rabbits and dogs have found the processes shortened, thickened and more rounded and displaced forwards towards the edge of the lens; the converse is seen after the use of atropin. Does not this prove that the whole retino-ciliary system is carried forward and that the fibres of the zonule are thereby relaxed? In view of his researches Beauvieux finds it very difficult to accept Tscherning's statement that "the place of insertion of the free part of the zonule corresponds to the summits of the ciliary processes or to a point slightly posterior to the summits ; it is almost on a level with the insertion of the muscle to the wall of Schlemm's canal and is necessarily drawn a little backwards by contraction of the muscle. It follows that the fibres which pass to the anterior surface of the lens, and whose direction is almost that of the muscle will be tense, while the fibres passing to the posterior surface will be relaxed." No zonule fibres are inserted at the level of Schlemm's canal; the anterior fibres arise high up on the pars plana, and even if some of the posterior groups spring from a lower site at the beginning of the ciliary processes, this region is, the writer thinks, far removed from the region of the muscle: Hence if it is correct that the ciliary muscle in contracting draws towards the centre of contraction its choroidal portion on the one hand and its point of attachment to the cornea on the other, it follows that the choroid, the ciliary part of the retina and the peripheral portion of the vitreous will be drawn forwards and the corneo-iridic angle will be pulled slightly backwards (the deepening of the angle of the anterior chamber during accommodation). But this action of the muscle would be without influence on the fibres of the zonule which as the author has demonstrated have a relation merely of contact and not of adhesion to the ciliary processes.

In considering solely the topographical relations of the zonule it is possible to maintain with Tscherning that the action of the posterior portion of the muscle draws the periphery of the vitreous towards the -crystalline lens; at the same time it increases the resistance of this part while diminishing that of the central retrolental part; on the other hand the contention of this observer that the contraction of the anterior part of the ciliary muscle exerts traction on the anterior lens capsule while causing relaxation of the posterior capsule appears to Beauvieux untenable from the anatomical point of view.

The author's research was almost finished when Marbaix 
published his paper on extraction of cataract in its capsule by the suction method of Barraquer without a vibratory vacuum ( $A n n$. d'Ocul., Nov., 1921). Beauvieux discusses some of the problems raised by his confrère, and Rochon-Duvigneaud has made some reservations concerning the operation as described by its inventor. The aim of the operator by Barraquer's method is rupture of the whole zonule at or near its attachment to the lens. The writer has shown that the ciliary processes and intervening hollows are merely covered in their posterior part by the suspensory ligament. They are therefore unimplicated, and he is convinced that complete extraction of the cataracatous lens by a vibratory vacuum has no ill-effect in their region. But is it certain that the vibrations of 45 to 65 centimetres of mercury used by Barraquer in certain forms of senile cataract induce rupture of the zonule fibres near their insertion into the capsule? Is it not probable that the rupture occurs further back and produces genuine tearing of the epithelium of the pars plana, or at least attrition of these elements which may explain the late cyclitis and irido-cyclitis recorded in literature of this subject? The author has frequently tried on enucleated eyes to remove the lens in its capsule by its posterior surface, and has noted a surprising resistance-the traction necessary being much greater than he expected. Rupture usually occurred in the free portion of the ligament, but some fibres were pulled away from the pars plana, bringing pigmentary debris with them. By the anterior surface on the contrary a gentle and persistent pressure induced rupture with much less effort. He thinks this is because the fibres are pulled in the bottom of the ciliary hollows and bent, so to speak, against the adjoining ridge; they then give way between this reflected portion and the attachment to the capsule. For this reason Beauvieux thinks extraction of the lens by means of suction, but without a vibration vacuum is a method more rational and less mutilating than that by means of vibratory vacuum. He has tried this plan on two enucleated human eyes and has established by examination that the fibres have given way at the level of the walls of the canal of Hannover, i.e., close to their insertion into the capsule. He would like to repeat this experiment with the eresiphake in order to compare the two methods from the histological point of view.

In his paper Beauvieux draws special attention to the relations of the crystalline lens and its suspensory ligament to the hyaloid and the vitreous, a relation of contact only, the hyaloid not being adherent except at the level of the ora serrata. The hyaloidcapsular ligament if it exists, is of the slenderest. This explains why it is easy to remove the lens in its entirety without fear of escape of vitreous. In Barraquer's operation loss of vitreous occurs only if there is faulty technique or sudden movement by the 
patient leading to rupture of the hyaloid. The author fears that phakoerisis with vibratory vacuum has sometimes a harmful effect on the " orbiculus ciliaris," the site of insertion of the zonule. Further experience will, without doubt, demonstrate the correctness or incorrectness of these anatomical deductions. The suggestion of Marbaix to extract in the capsule by simple nonvibratory suction is, in the author's opinion, very judicious and deserving of attention.

J. B. LAWFORD.

\section{BOOK NOTICES}

Ophthalmological Society of Egypt. Bulletin of 1922. Cairo, 1922.

This volume of 92 pages includes the proceedings of the 19th Annual Meeting of the Ophthalmological Society of Egypt held on March 31, 1922, at the Kasr El Ainy Medical School, under the presidency of Dr. Mohammed Bey Saleh. Sixty members were present. It will be remembered that the Society issued a report on the means of prophylaxis against trachoma, etc. (see Brit. Jl. of Ophthal., March, 1922, p. 126).

The Minister of Education took exception to this report. The Bulletin now prints a reply, in the course of which it says: "The Committee are not prepared to alter their report by a single paragraph." The Bulletin contains many interesting communications. Mr. MacCallan enters fully into a description of 15,619 cases of blind patients who applied for treatment at the Egyptian ophthalmic hospitals during 1921 , or 12.2 per cent. of the patients. Conjunctivitis accounted for the great majority of the blind. Other notable causes were glaucoma, cataract, endogenous iritis, optic atrophy and injury. Dr. Tewfik speaks well of injections of milk and records a case of gonorrhoeal ophthalmia with corneal complications and of abscess of the orbit and of a dendritic ulcer of the cornea successfully treated by that means. Dr. R. V. Dolbey, during the last fifteen months, has met with four cases of ethmoidal sinus suppuration simulating orbital tumour. Dr. M. Riad examined the fundi in twenty cases of severe anaemia due to ankylostoma worm infection. When haemoglobin in the blood varied from 60 to 70 per cent. nothing was found in the fundi except dilatation of the veins and slight paleness in the colour of the choroidal reflex. When the haemoglobin varied between 30 and 50 per cent. the choroidal reflex was of a light yellow colour and the retinal veins resembled flattened ribbons. In one of these cases there were a few white dots along the right superior temporal artery, with two flame-shaped haemorrhages in the inferior 